\section{A CASE OF CARCINOMA OF THE JEJUNUM; WITH REMARKS ON MALIGNANT DISEASE OF THE SMALL INTESTINE.}

BY CHARLES R. KEYSER, F.R.C.S. ENG.,

ASSTSTANT SURGEON TO THE CANCER HOSPITAL, BROMPTON, S.W. CONSULTING SURGEON TO THE ELIOT COTTAGE HOSPITAL, HAYWARDS HEATE.

THE patient, a female, aged 38 years, was admitted into the Cancer Hospital, Brompton, on March 9th, 1908, and gave the following history. Ten months previously she had been confined and three days later had noticed abnormal abdominal pulsation. She had called the attention of her medical attendant to it and he had discovered an abdominal tumour and had sent her to St. Bartholomew's Hospital where an exploratory incision was made, but it was found impossible to remove the tumour. The swelling had caused her more or less constant pain in the abdomen and some difficulty in micturition, but no rectal symptoms. Since the birth of her child she had had amenorrhoea and had been gradually losing flesh. There had been no vomiting. The patient was pale and anæmic and looked ill. The abdomen showed a marked tumour and there were some dilated veins visible in the skin. On palpation most of the abdominal cavity was found to be occupied by a large, firm, bossed swelling, the exact extent of which it was difficult to determine. It consisted chiefly of two marked prominences on each side of the umbilicus, the one on the right side receiving strong pulsations from the aorta and common iliac arteries. The tumour extended almost as far as the costal margin and on the left side nearly filled up the loin. It did not appear to dip down into the true pelvis. The most prominent parts of the swellings were dull on percussion and the rest of the abdomen gave a note of modified resonance. The flanks were resonant. There was a well-marked sulcus to be felt between the two prominent masses and here the abdomen was softer to the touch than elsewhere. The tumour appeared to be absolutely fixed by its deeper parts, but there was a slight lateral mobility to be made ont on grasping the superficial parts of the growth. Per vaginam the uterus was anteverted, moveable, and quite distinct from the abdominal swelling and the latter did not depress the vaginal fornices. The urine was acid, with a specific gravity 1030, and it contained some albumin. The patient was kept in bed but was allowed up for an hour or so in the evening. On March 12th she complained of some pain in the left side during the morning, but got up in the evening as usual. Suddenly whilst walking about she was seized with very acute pain in the left side, chiefly in the upper vart; she became very collapsed and vomited. On examination the abdomen was found to be rigid, especially the left upper part, and very tender and immoveable on respiration. The temperature was normal, but the pulse was 130 and the respirations were 30 , and both the latter were increasing in rate. The vomiting persisted. It was obvious that some abdominal catastrophe had occurred and it was thought that either the bowel had ruptured at its attachment to the growth or that a perforation of the stomach had taken place.

Although the prognosis was very bad, at 9.30 P.M. I opened the abdomen in the left semilunar line above the umbilicus. On dividing the peritoneum an enormous growth was encountered matting together nearly all the contents of the abdomen. The tumour was firmly fixed at its base, and to it the greater part of the transverse and descending colon was so intimately adherent that it was not possible to lift any of it into the wound. No perforation could be seen or felt, so the wound was enlarged upwards and an attempt made to bring the stomach into view. This also was impossible, but from behind the cardiac end of the stomach about a pint of turbid, inoffensive fluid welled up. This was mopped up with swabs, and as it was hopeless to try to find the perforation two large drainage tubes were inserted into the cavity whence the fluid came; one from the original wound in the anterior abdominal wall and a second from a stab wound made in the left loin. The abdomen was rapidly closed, as the patient's condition did not admit of any delay. She was much collapsed after the operation and hardly rallied, although stimulants were freely given both by the rectum and hypodermically. On the following day it was obvious that the patient was dying; the pulse was over 160 and the respirations were 40 . Vomiting persisted and at times appeared to be becoming fæcal in character. She died at 6 P.M. on March 13th.

Dr. Alexander Paine, director of the pathological department of the hospital, conducted the post-mortem examination and found the condition of affairs to be as follows. On opening the abdomen the small intestine was seen to be intensely injected and the separate coils adherent by inflammatory lymph. About three or four ounces of sanious, purulent fluid had collected in the pelvic basin, and bands of easily friable lymph were stretched between the abdominal viscera and the parietes, the result of septic peritonitis. In the middle line was a large tumour in front of the spine occupying the middle of the epigastrium, appearing as a rounded irregular swelling with a nodular surface, just below the transverse colon. The omentum did not cover it since the latter structure was drawn over to the left side. The tumour was of the size of two closed fists and was directed rather towards the right of the middle line. On the left of the middle line was a second mass or tumour of the size of a small cocoanut situated in the left hypochondrium just below the stomach and posterior to the colon, which ran over its upper margin. This was rather smooth on the surface and was attached behind to the body of the pancreas. Its inner margin was attached firmly to a fluctuating mass of the size of a large cocoanut which was situated in the lateral aspect of this region just below the stomach and spleen. The walls of this mass were very thin and rapidly broke down. On dissection it was found to be the first portion of the jejunum, the lumen of which was distended but not obstructed by an extensive growth several inches in length covering the inner surface. Although it was not possible to discover anything of the nature of a small opening this was probably the seat of peritoneal infection (septic). No further evidence of growth was found in the abdomen. (Figs. 1 and 3.) The stomach was markedly distended and together with the liver, which was enlarged and fatty, plus masses of growth pushed up the diaphragm and encroached on the thorax to some extent. Microscopically, the growth was a columnar-celled carcinoma of an atypical kind. Some of the cells were spheroidal in shape whilst others showed a transition between the two forms. In places the sections looked more like a mixed-celled sarcoma than a carcinoma, but Mr. S. G. Shattock, who very kindly examined the specimens for me, agreed with Dr. Paine that the growth was a columnar-celled carcinoma. (Fig. 2.)

Cancer of the intestinal tract is usually found at those points where there is a change in the lining epithelium of the canal, such as the junction of the œsophagus and stomach, the anus, \&c.,or where the canal is subjected to some form of irritation, such as the sigmoid colon and rectum, the hepatio and splenic flexures of the colon, or the cæcum. The small intestine, being a tube which is free from sudden bends and containing only liquid matter, is seldom attacked by carcinoma. Nevertheless, these parts are occasionally, though very rarely, the seat of cancer. Of the three portions of the small intestine-duodenum, jejunum, and ileum-the first named is much oftener affected than the other two; in fact, cancer of the duodenum alone is said to occur about as frequently as cancer of the jejunum and ileum together (Nothnagel ${ }^{1}$ ). The rarity of the disease, especially in the jejunum, may be judged from the following statistics. In 24 years from 1870-1893 inclusive there were 41,838 necropsies conducted at the Pathologic Institute of the Vienna General Hospital. Among these there were 3585 cases of carcinoma, and 343 of these were in the intestines. Seven occurred in the duodenum, ten in the ileum, and none in the jejunum. Leichtenstern $^{2}$ collected 757 cases of carcinoma of the intestines from living and post-mortem cases. Of these 13 were in the lower ileum, three in the middle ileum, and 17 in the duodenum. Muller, ${ }^{3}$ from $1886-1891$ at the Pathologic Institute of Bern, records 5621 post-mortem examinations and 521 cases of cancer of the intestines. Of these, nine were in the small intestines, six being in the duodenum. Brill $^{4}$ quotes a large number of cases of intestinal cancer

1 Diseases of the Intestine and Peritoneum, English edition. 3 Quoted by Nothnagel.

4 American Journal of the Medical Sciences, Philadelphia, 1904. 
collected from various sources and finds that $2 \cdot 5$ per cent. $\quad$ Mayo Robson, ${ }^{10}$ Glynn, ${ }^{11}$ Hammer, ${ }^{12}$ and Notthaft. ${ }^{13}$ occurred in the small intestine. A, Zemann ${ }^{5}$ in 21,624 post- Barnard, at the London Hospital, found two instances out of mortem examinations found nine cases of cancer of the small 481 cases of carcinoma of the intestines. From 1896-1907 intestine, of which three were in the duodenum, six in the inclusive only one case has been recorded at St. Bartholoileum, and none in the jejunum. C. Hemann, ${ }^{6}$ whose mew's Hospital. One case only has also been recorded at statistics are quoted as being most reliable, records 1706 Guy's Hospital. Mr. C. W. Rowntree, of the Cancer Research

FIG. 1.

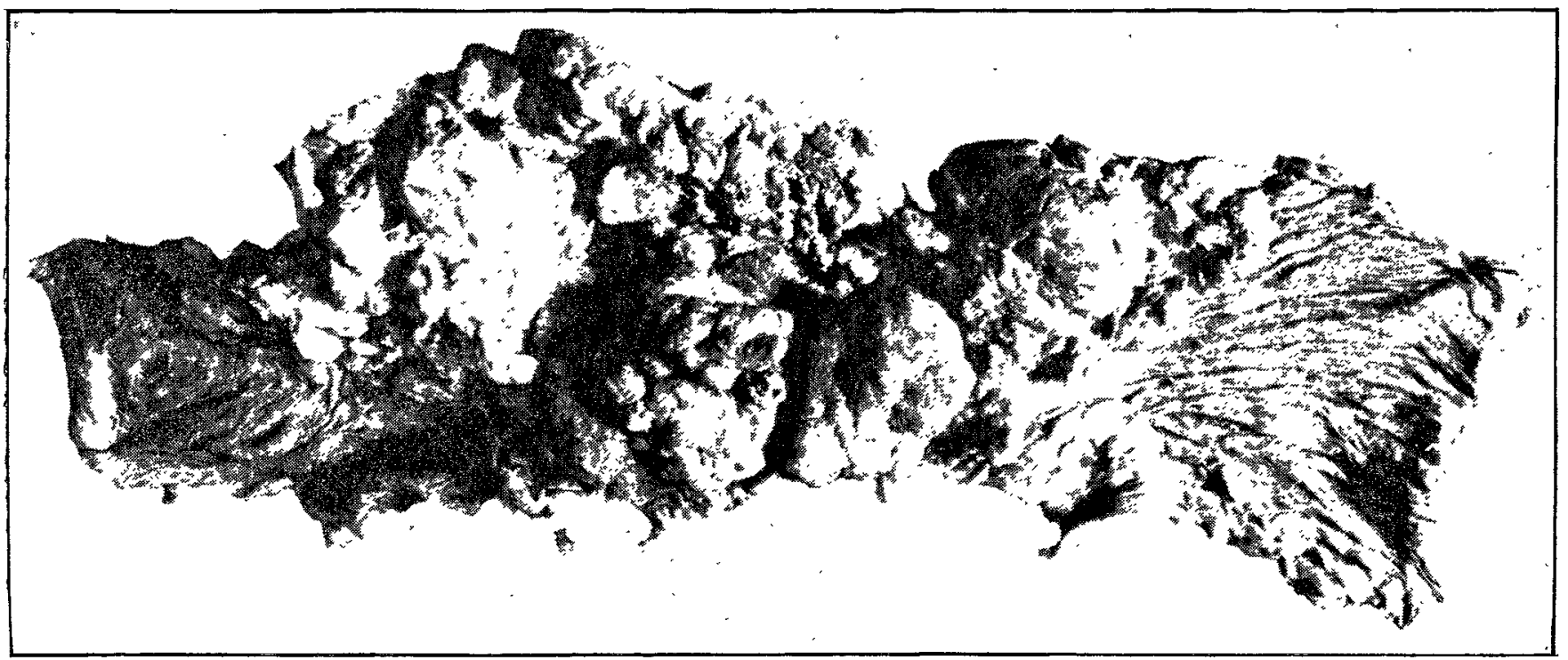

Primary carcinoma of the jejunum.

cases of carcinoma of the intestines. These were collected from those patients who died in the general hospitals of Prussia during the years 1895-96. 20 of these occurred in the small intestine. Lubarsch, ${ }^{7}$ from necropsies at the Pathologic Institute of the hospital at Breslau, found 569 cases of intestinal cancer; two of these were in the duodenum and two in the ileum.

FIG. 2.

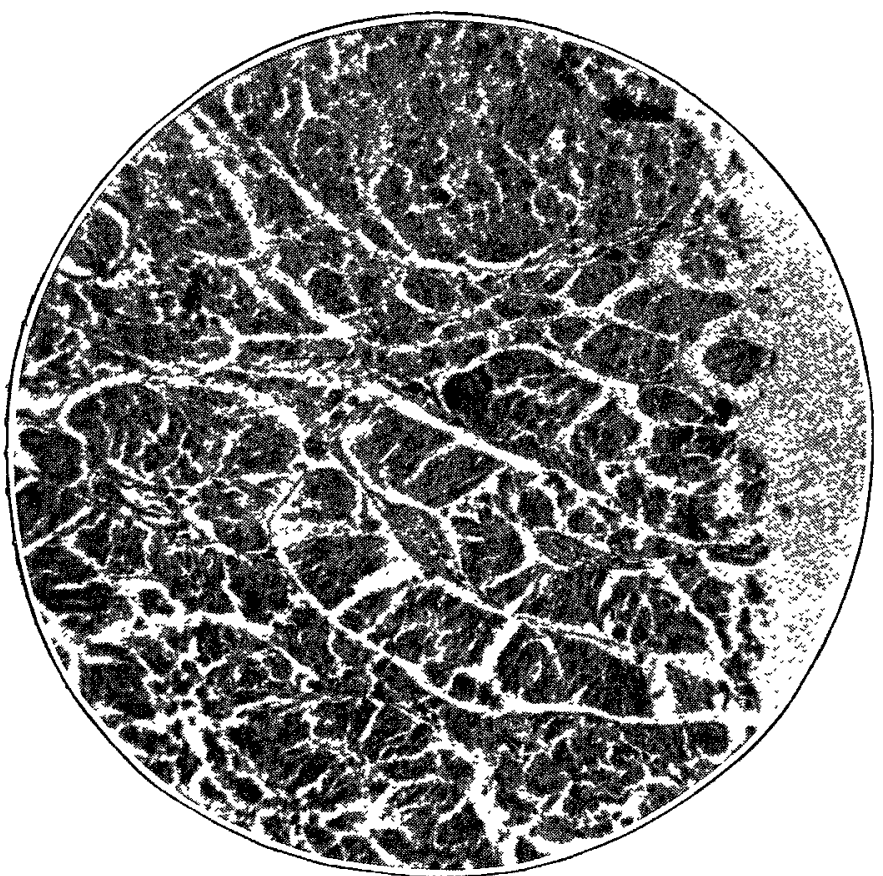

Primary carcinoma of jejunum, showing columnar and spheroidal cells, also transition forms. Microphotograph by Dr. T. J. English. $\times 200$ diameters.

From the statistics quoted above only those from the Pathologic Institute of the Vienna General Hospital and Zemann mention cancer of the jejunum apart from cancer of the small intestine, but these alone indicate sufficiently the rarity of the disease, as out of 63,462 post-mortem examinations not a single case was found. Isolated cases of jejunal cancer are recorded, however, by Fagge, ${ }^{8}$ Voelcker, ${ }^{9}$ 567 Quoted by Nothnagel.

Rrit. Med Jour 1907, vol. i., p. 262

9 Transactions of the Pathological Society of London, vol. xliv., p. 88.
Laboratories, informs me that during the last five years at the Middlesex Hospital 1169 cases of carcinoma have been investigated; these cases included only one of cancer of the

FIG. 3.

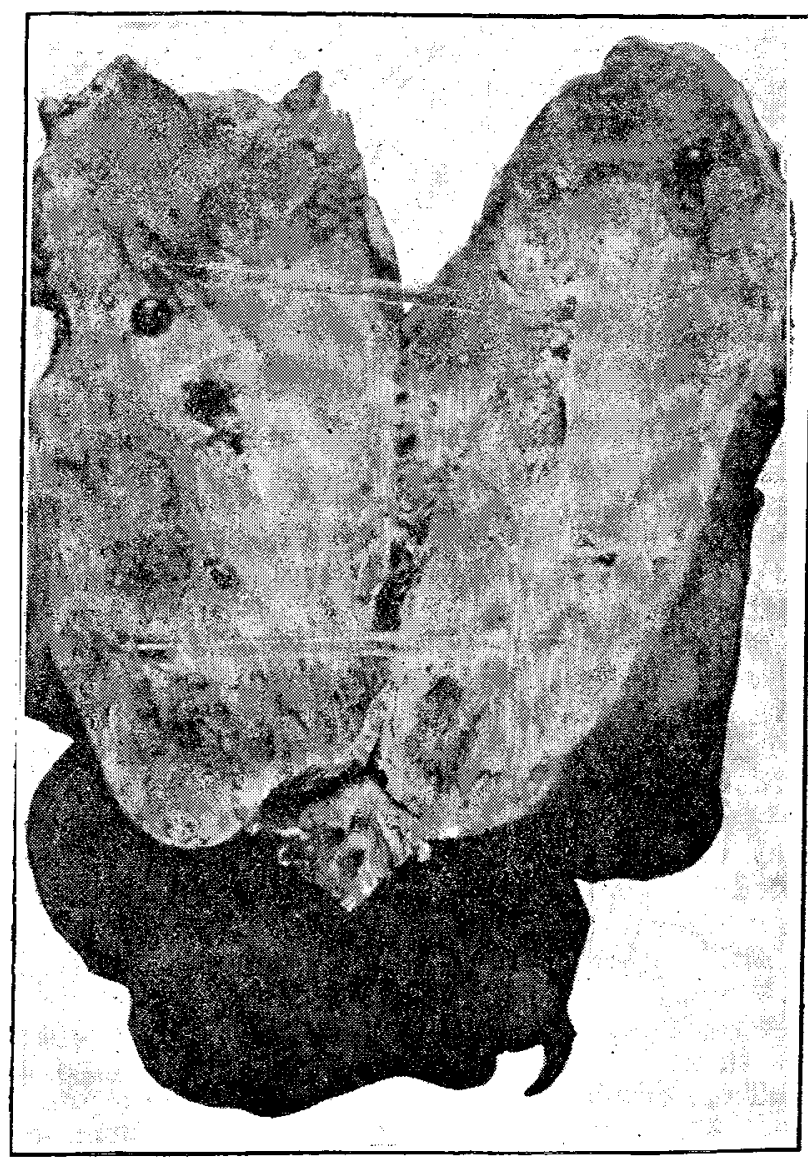

One of the secondary growths.

jejunum. No cases have been recorded at st. George's, Charing Cross, or the Cancer Hospitals.

10 Transactions of the Clinical Society of London, rol. xxix., p. 40. 11 Brit. Med. Jour., 1908, rol. i., p. 624

12 Prager Medicinische Wochenschrift, 1896, Band xxi., p. 212.

13 Deutsches_Archiv für Klinische Medicin, 1895, vol. liv., p. 555 
As duodenal cancer presents more or less special features both in pathology and symptoms, only carcinoma of the jejunum and ileum will be discussed in this paper. A considerable number of cases of cancer of the ileum have been collected and many examples of the disease can be found in the museums of the London hospitals. Bunting, ${ }^{14}$ however, has recorded one and quoted six others which are of especial interest as there were multiple primary growths present. These cases were also characterised by their relative benignity, the small size of the tumours, the spheroidalcelled nature of the growths, which resembled primary carcinoma of the vermiform appendix, and by not causing the death of the patients. It must be remembered, however, that it is possible that some of the cases quoted as cancer of the ileum are instances of growth affecting the ileo-cæcal valve and therefore are classified by some authors as cancer of the large intestine and by others as cancer of the small intestine.

The symptoms of cancer of the small intestine are practically the same as those of the upper part of the colon-viz., pain, often colicky in nature, a tendency to constipation with occasional diarrhcea, anæmia, and later in the disease cachexia. Occasionally repeated violent hæmorrhages from the anus are seen. A tumour can be felt when the disease is advanced, but is most difficult to find in the early stages owing to the mobility of the small intestine.

Table of 12 Cases of Carcinoma of the Jejunum, showing the Chief Symptoms.

\begin{tabular}{|c|c|c|c|c|c|c|}
\hline 总 & $\dot{d}$ & Pain. & Tumour. & $\begin{array}{l}\text { Vomit- } \\
\text { ing. }\end{array}$ & $\begin{array}{l}\text { Obstruc- } \\
\text { tion. }\end{array}$ & Remarks. \\
\hline 33 & F. & - & Rightiliac. & Yes. & No. & - \\
\hline 33 & M. & - & - & - & No. & - \\
\hline 33 & F. & Yes. & Left iliac. & - & - & Sudden perforation. \\
\hline 49 & M. & Yes. & No. & Yes. & $\begin{array}{c}\text { Yes, } \\
\text { chronic. }\end{array}$ & 一 \\
\hline 33 & F. & Yes. & No. & Yes. & - & Sudden perforation. \\
\hline 52 & F. & Yes, & No. & - & - & - \\
\hline 35 & $?$ & Yes. & - & Yes. & - & - \\
\hline 36 & $M$. & Yes. & Left iliae. & - & - & Sudden perforation \\
\hline 63 & M. & Yes. &,$\quad$, & - & - &, \\
\hline 56 & M. & Vague. & Left side. & Once. & - & Bowels open daily. \\
\hline 60 & M. & - & - & - & - & - \\
\hline 38 & $\mathrm{~F}$. & Yes. & Yes. & No. & No. & Sudden perforation. \\
\hline
\end{tabular}

When palpable it is, in the majority of cases, to be felt in the iliac fossa, most commonly the left, and not in the upper part of the abdomen (vide table). Vomiting is not uncommon but symptoms of obstruction are rarely seen, unless the disease is close to the ileo-crcal valve. In my case and in one other (Barnard) the lumen of the gut was dilated; in any case the annular form of growth, which is so frequently seen in the large intestine, is rarely found. Sudden perforation of the gut with resulting peritonitis not uncommonly occurs, when death almost invariably follows. In several cases of carcinoma of the ileum where the symptoms were detailed the patients were admitted to hospital and died from some other disease, the neoplasm being found accidentally at the post mortem examination.

Age.-Out of 11 cases of carcinoma of the jejunum which I have collected the average age at which the disease was discovered was $43 \cdot 9$, but in six out of the 11 the age was under 40. In carcinoma of the ileum the average age seems to be a little higher; thus out of 13 cases the average age was 50.

Sex.-Cancer of the jejunum and ileum does not appear to occur with much greater frequency in one sex than in the other. Thus out of 11 cases of cancer of the jejunum six were males and five were females. In carcinoma of the ileum out of 14 cases eioht were males and six were females.

Pathology. - The chief point of interest to be mentioned under this head is that the growth frequently shows spheroidal- as well as columnar-shaped cells. In some instances the growth is entirely spheroidal-celled. In others the cells are of such different shapes that the microscopical appearance resembles that of a mixed-cell sarcoma with

14 Johns Hopkins Hospital Bulletin, 1904, vol. xv., p. 389. alveolar arrangement of the cells. Sarcoma of the small intestine is not of such rarity as carcinoma and occurs about as frequently in the small as in the large intestine. In fact, cases of lympho-sarcoma preponderate in the small intestine. Nothnagel quotes the following: Out of 12 cases of lymphom sarcoma of the intestine one was in the duodenum, three were in the jejunum, four in the ileum, three in the cæcum, and one in the rectum. In Prague out of 13 cases of intestinal sarcoma occurring in 15 years seven were in the ileum, three. in the jejunum and ileum, and three in the cæcum. Libman ${ }^{1 \overline{5}}$ collected 15 cases in the duodenum, 18 in the jejunum and ileum, 14 in the ileum, and three cases affecting the entire length of the small intestine. Out of 37 cases Krueger ${ }^{16}$ found 16 in the small intestine. Corner and Fairbank ${ }^{17}$ collected 65 cases; of these, eight were in the duodenum, 19 in the jejunum, and 29 in the ileum. In nine the exact situation was not stated. The symptoms are the same as those of carcinoma of the small intestine.

Treatment. - If the case is seen early enough or a growth is discovered during the performance of an exploratory laparotomy enterectomy and end-to-end anastomosis should be performed if this is possible. If symptoms of intestinal obstruction are present and the neoplasm is irremoveable a lateral anastomosis should be done.

For permission to publish this case $I$ am indebted to Mr. F. Bowreman Jessett, senior surgeon to the hospital, and for the notes of the case to Mr. T. B. Henderson, surgical registrar to the hospital, while I have to thank Dr. T. J. English for the excellent photographs which he has taken for me.

Queen Anne-street, W.

\section{A NOTE ON THE TREATMENT OF ERYSIPELAS.}

BY H. TYRRELL GRAY, M.A., M.C.C.ANTAB., F.R.C.S.ENG., RESIOEAT MEDICAL SUPERINTENDENT, HOSPITAL FOR SICK CHIIDREY, GREAT ORMOND STREET, LONDON.

IN considering the methods of treating cutaneous erysipelas it is necessary to mention both the local and constitutional means of combating this infection. With regard to local measures very little need be said, because the recovery of the patient depends less upon the treatment of the infected area than upon the means adopted to increase the general resistance of the tissues against the disease. The local treatment may therefore be dismissed by saying that the infected part should be kept dry by dusting with powder; calomel, zinc oxide, and starch in equal parts were used in the following cases and this is usually cooling and welcome to the patient as it relieves the burning pain so commonly complained of.

The constitutional treatment may be medicinal only or combined with vaccination or the use of sera. Of vaccination in cases of erysipelas I have no practical experience and cannot therefore discuss its value ; but the cases here outlined with their temperature charts speak, I think, in favour of the use of Metchnikoff's serum in this disease, especially when combined with the internal administration of quinine, stimulants, \&c. The results of the use of antistreptococcal serum seem to me to have been variable, more striking with some patients than with others; and, while I am well aware that the following series of cases is too small to warrant any decided opinions, a further trial of Metchnikoff's serum seems justified by the similarity of the results obtained. In all the cases below the dose of serum is assumed to be from 40 to 50 minims, unless otherwise stated.

CASE 1.-The patient, a girl, aged one and a half years, was admitted into hospital for two large abscesses, one on each side of the neck, which were opened and drained on May 9th, 1907. (Fig. 1.)

Streptococcus pyogenes was grown in pure culture from the pus evacuated. On the 12 th a severe attack of erysipelas manifested itself and spread rapidly to both sides of the face in succession, constitutional symptoms being marked. The chart shows that the temperature commenced to fall definitely about the third day from the commencement of

$$
1516 \text { Quoted by Nothnagel. }
$$

17 Transactions of the Pathological Society of London, vol. 1vi., p. 20. 